\title{
Infective Endocarditis in Childhood: a Single- Center Experience of 18 Years
}

\author{
Kahraman Yakut ${ }^{2}$, MD; Zafer Ecevit ${ }^{1}$, MD; Niyazi Kursad Tokel ${ }^{2}$, MD; Birgul Varan², MD; Murat Ozkan³ ${ }^{3}$ MD
}

DOI: $10.21470 / 1678-9741-2020-0035$

\begin{abstract}
Introduction: We aimed to present the risk factors, clinical and laboratory findings, treatment management, and risk factors for morbidity and mortality of infective endocarditis (IE) as well as to relate experiences at our center.

Method: We retrospectively analyzed data of 47 episodes in 45 patients diagnosed with definite/possible IE according to the modified Duke criteria between May 2000 and March 2018.

Results: The mean age of all patients at the time of diagnosis was 7.6 \pm 4.7 years (range: 2.4 months to 16 years). The most common symptoms and findings were fever (89.3\%), leukocytosis $(80.8 \%)$, splenomegaly $(70.2 \%)$, and a new heart murmur or changing of pre-existing murmur (68\%). Streptococcus viridans $(19.1 \%)$, Staphylococcus aureus $(14.8 \%)$, and coagulase-negative Staphylococci $(10.6 \%)$ were the most commonly isolated agents.
\end{abstract}

IE-related complications developed in $27.6 \%$ of the patients and the mortality rate was $14.8 \%$.

Conclusion: We found that congenital heart disease remains a significant risk factor for IE. The highest risk groups included operated patients who had conduits in the pulmonary position and unoperated patients with a large ventricular septal defect. Surgical intervention was required in most of the patients. Mortality rate was high, especially in patients infected with $S$. aureus, although the time between the onset of the first symptom and diagnosis was short. Patients with fever and a high risk of IE should be carefully examined for IE, and evaluation in favor of IE until proven otherwise will be more accurate. In high-risk patients with prolonged fever, IE should be considered in the differential diagnosis.

Keywords: Endocarditis. Staphylococcus Infections. Congenital Heart Defects. Anti-Bacterial Agents. Heart Murmurs.

\section{INTRODUCTION}

Infective endocarditis (IE), which develops because of bacterial, viral, or fungal agents, is an infection of the endocardium. Although IE often affects the heart valves, it may also cause septal defects or mural endocarditis. IE is less common in children than in adults, and it is associated with high morbidity and mortality due to prolonged treatment time and related complications. The incidence of IE in children is 0.43 per 100,000 children $^{[1]}$. Its risk factors include congenital heart disease (CHD), rheumatic heart diseases (RHD), and bacteremia due to hospital-acquired infections, with $\mathrm{CHD}$ being the main risk factor. Currently, increased invasive interventions and longterm use of central venous catheters increase the risk of IE in patients without an underlying heart disease.

'Department of Pediatric Infectious Diseases, Baskent University School of Medicine, Ankara, Turkey.

2Department of Pediatric Cardiology, Baskent University School of Medicine, Ankara, Turkey.

${ }^{3}$ Department of Cardiovascular Surgery, Baskent University School of Medicine, Ankara, Turkey.

This study was carried out at the Department of Pediatric Cardiology, Baskent University School of Medicine, Ankara, Turkey.
In this study, we present the clinical, diagnostic, and microbiological characteristics of patients with IE who were followed up at a tertiary care hospital that is an important pediatric cardiovascular and cardiac surgery center in Turkey.

\section{METHODS}

The data of pediatric patients (aged $\leq 18$ years) diagnosed with definite/possible IE episodes according to the modified Duke criteria ${ }^{[2]}$ and followed up at our clinic between May 2000 and March 2018 were retrospectively analyzed. This study was approved by the Ethics Committee of our university (KA17/21615.08.2017). The clinical and laboratory findings, demographic and echocardiographic characteristics, pathological and culture findings, vegetation localization, underlying disease, acquired

Correspondence Address:

Kahraman Yakut

(iD) https://orcid.org/0000-0002-9221-5636

Department of Pediatric Cardiology, Baskent University School of Medicine

Fevzi Çakmak Cad. 10. Sok. No: 45, Bahçelievler, Ankara, Turkey

Zip Code: 06490

E-mail:kahramanyakut@gmail.com

Article received on January $23^{\text {rd }}, 2020$. Article accepted on March 26 ${ }^{\text {th }}, 2020$. 


\begin{tabular}{|c|c|c|c|}
\hline \multicolumn{2}{|c|}{ Abbreviations, acronyms \& symbols } & \multirow[b]{2}{*}{ IVC } & \multirow[b]{2}{*}{ = Inferior vena cava } \\
\hline ABV & $=$ Aortic balloon valvuloplasty & & \\
\hline ALT & = Alanine aminotransferase & L-AVVR & $=$ Left atrioventricular valve regurgitation \\
\hline APV & $=$ Absent pulmonary valve & LA & $=$ Left atrium \\
\hline AR & $=$ Aortic regurgitation & LVOT & $=$ Left ventricle outflow tract \\
\hline ARF & $=$ Acute rheumatic fever & MR & $=$ Mitral regurgitation \\
\hline AS & $=$ Aortic stenosis & MV & $=$ Mitral valve \\
\hline ASD & $=$ Atrial septal defect & MVR & $=$ Mitral valve replacement \\
\hline ASO & $=$ Arterial switch operation & NICU & $=$ Neonatal intensive care unit \\
\hline AST & $=$ Aspartate aminotransferase & PA & $=$ Pulmonary atresia \\
\hline AV & $=$ Aortic valve & PAVSD & $=$ Partial atrioventricular septal defect \\
\hline AVR & $=$ Aortic valve replacement & PC & $=$ Pulmonary conduit \\
\hline BAV & = Bicuspid aortic valve & PS & $=$ Pulmonary stenosis \\
\hline BCA & = Balloon coarctation angioplasty & PTFE & $=$ Polytetrafluoroethylene \\
\hline BT & = Blalock-Taussig & PV & $=$ Pulmonary valve \\
\hline C-TGA & $=$ Corrected transposition of the great arteries & R-AVV & $=$ Right atrioventricular valve \\
\hline CAVSD & $=$ Complete atrioventricular septal defect & R-AVVR & $=$ Right atrioventricular valve regurgitation \\
\hline CHD & $=$ Congenital heart disease & RA & $=$ Right atrium \\
\hline CIED & = Cardiac implantable electronic device & RHD & $=$ Rheumatic heart diseases \\
\hline CoA & $=$ Coarctation of the aorta & RV-PA & $=$ Right ventricular-pulmonary artery \\
\hline CoNS & = Coagulase-negative Staphylococci & RVOTR & $=$ Right ventricular outflow tract reconstruction \\
\hline CRP & = C-reactive protein & SVC & $=$ Superior vena cava \\
\hline CT & $=$ Computed tomography & TEE & $=$ Transesophageal echocardiography \\
\hline DORV & $=$ Double outlet right ventricle & TGA & $=$ Transposition of the great arteries \\
\hline DSM & $=$ Discrete subaortic membrane & TOF & $=$ Tetralogy of Fallot \\
\hline \multirow[t]{3}{*}{ HACEK } & = Haemophilus species, Aggregatibacter species, & TTE & = Transthoracic echocardiography \\
\hline & Cardiobacterium hominis, Eikenella corrodens, & TV & $=$ Tricuspid valve \\
\hline & and Kingella species & VSD & $=$ Ventricular septal defect \\
\hline IE & $=$ Infective endocarditis & & \\
\hline
\end{tabular}

heart valve diseases, central catheter or cardiac implantable electronic device (CIED) use, previous surgical interventions, complications, transthoracic echocardiography (TTE) and transesophageal echocardiography (TEE) findings, history of broad-spectrum antibiotic use, history of hospitalization in a long-term intensive care unit, and length of hospital stay were evaluated in all patients. Furthermore, the erythrocyte sedimentation rate, C-reactive protein (CRP) level, complete blood count, and liver and kidney functions were examined before and after treatment. TTE was performed in all patients, and TEE and/or multislice computed tomography (CT) was performed if needed.

$\mathrm{CHD}$, which was included in the risk group, was examined in two subgroups, i.e., simple and complex CHD. Other risk factors included acquired heart disease, malignancy, history of broadspectrum antibiotic use, history of hospitalization in a longterm intensive care unit, and use of central catheter or CIEDs for another disease.

Patients who met the pathological criteria according to the modified Duke criteria and those who met two major criteria, one major and three minor criteria, or five minor criteria according to the clinical criteria were considered to have definite $I E$, whereas those who met one major and one minor criterion or three minor criteria were considered to have possible IE. Repeated IE occurrence after the treatment of the first episode was defined as recurrent IE. In cases in which the appearance of endocarditis symptoms or positive blood cultures was observed $48 \mathrm{~h}$ after admission or in which IE was diagnosed within eight weeks after cardiac surgery or catheterization, the patients were considered to have nosocomial IE.

\section{Statistical Analysis}

Statistical analysis was performed using the PASW version 17.0 software (SPSS Inc., Chicago, Illinois, United States of America). Descriptive statistics were expressed as mean \pm standard deviation and frequency. A P-value $<0.05$ was considered statistically significant.

\section{RESULTS}

\section{Demographic Characteristics}

A total of $47 \mathrm{IE}$ episodes were detected in 45 patients. Among these IE episodes, 34 (72.3\%) were definite and 13 (27.6\%) were possible IE episodes according to the modified Duke criteria. The 
mean age of the patients at the time of diagnosis was 7.6 \pm 4.7 years (range: 2.4 months to 16 years). In addition, 36 IE episodes (76.6\%) were noted in males and 11 (23.4\%) in females. Eight patients (17\%) were aged < 1 year, seven (14.8\%) were aged 2-5 years, 20 (42.5\%) were aged 6-10 years, and 12 (25.5\%) were aged $11-18$ years.

At least one risk factor was observed in all IE episodes, with the most common risk factor being CHD ( $n=41,87.2 \%)$. Furthermore, 22 IE episodes (46.8\%) involved complex CHD and 19 (40.4\%) involved simple CHD. The most notable CHD included patients who underwent surgery and had conduit insertion at the pulmonary position (29.8\%) as well as those with untreated ventricular septal defect (VSD) (23.4\%) (Table 1). Risk factors other than CHD included heart valve disease associated with RHD in three patients (6.4\%), a history of long-term central catheterization and follow-up after broad-spectrum antibiotic therapy in two patients (4.3\%), and a history of permanent dialysis catheter inserted into the right subclavian vein in one patient (2.1\%). Three patients had a prosthetic valve; one of these patients underwent aortic valve replacement due to severe aortic

Table 1. Diagnosis of patients and surgical procedures before infective endocarditis episodes.

\begin{tabular}{|c|c|c|c|}
\hline Diagnosis & Surgical & Foreign material & Vegetation area \\
\hline VSD & No & & MV, VSD-left side \\
\hline VSD & No & & VSD-right side \\
\hline VSD & No & & Native-PV \\
\hline VSD & No & & TV, PV \\
\hline VSD & No & & MV \\
\hline VSD & No & & TV \\
\hline VSD & No & & TV \\
\hline VSD & No & & TV \\
\hline VSD & No & & TV, PV \\
\hline VSD & No & & Abscess between the RA and aorta \\
\hline VSD & No & & VSD-right side \\
\hline VSD & VSD-repair & & TV \\
\hline PAVSD, MR, TR, DSM & PAVSD-repair & & $\mathrm{AV}$ \\
\hline TOF & TOF-complete repair & & VSD patch-right side \\
\hline TOF & Modified BT shunt & PTFE graft & TV \\
\hline TOF & TOF-complete repair & Biological valved conduit & $P C$ \\
\hline TOF, atrioventricular block & TOF-complete repair & $\begin{array}{l}\text { Biological valved conduit, dual } \\
\text { chamber pacemaker lead }\end{array}$ & PC \\
\hline $\mathrm{BAV}, \mathrm{AS}$ & $\begin{array}{c}\text { Modified Konno, AVR, } \\
\text { MVR }\end{array}$ & Prosthetic MV and AV & Prosthetic MV \\
\hline $\mathrm{BAV}, \mathrm{AS}, \mathrm{MR}$ & ABV & & $\mathrm{AV}$ \\
\hline$B A V, A S, A R$ & Ross & Biological valved conduit & $\mathrm{AV}$ \\
\hline $\mathrm{BAV}, \mathrm{AS}, \mathrm{MR}$ & ABV & & $\mathrm{AV}$ \\
\hline COA, DSM & $\mathrm{BCA}$ & & MV \\
\hline$D S M, A R$ & DSM resection & & LVOT, AV \\
\hline TGA, ASD & ASO, ASD-repair & & LVOT, AV \\
\hline TGA, ASD & ASO, ASD-repair & & $M V, L A$ \\
\hline TGA, VSD, ASD, PS (mild) & ASO, VSD and ASD-repair & & Absent vegetation \\
\hline TGA, VSD, ASD, PS (mild) & ASO, VSD and ASD-repair & & $\mathrm{AV}, \mathrm{PV}$ \\
\hline TGA, VSD, ASD, PS & Rastelli surg, ASD-repair & Biological valved conduit & $P C$ \\
\hline
\end{tabular}




\begin{tabular}{|c|c|c|c|}
\hline TGA, VSD, ASD, PS & Rastelli surg, ASD-repair & Biological valved conduit & PC \\
\hline TGA, VSD, ASD, PS & Modified BT shunt & PTFE graft & Native-PV \\
\hline DORV, VSD, PS & $\begin{array}{c}\text { Rastelli surg, RVOTR with } \\
\text { conduit }\end{array}$ & Biological valved conduit & PC \\
\hline DORV, VSD, PS & $\begin{array}{c}\text { Rastelli surg, RVOTR with } \\
\text { conduit } \\
\end{array}$ & Biological valved conduit & PC \\
\hline DORV, VSD, PS & $\begin{array}{l}\text { Rastelli surg, RVOTR with } \\
\text { conduit }\end{array}$ & Biological valved conduit & TV \\
\hline DORV, VSD & Pulmonary banding & & Absent vegetation \\
\hline$A P V, V S D$ & $\begin{array}{l}\text { RVOTR with conduit, VSD } \\
\text { repair }\end{array}$ & Biological valved conduit & PC \\
\hline$A P V, V S D$ & $\begin{array}{l}\text { RVOTR with conduit, VSD } \\
\text { repair }\end{array}$ & Biological valved conduit & PC \\
\hline PA, VSD & $\begin{array}{l}\text { RVOTR with conduit, VSD } \\
\text { repair }\end{array}$ & Biological valved conduit & PC \\
\hline PA, VSD & $\begin{array}{l}\text { RVOTR with conduit, VSD } \\
\text { repair } \\
\end{array}$ & Biological valved conduit & PC \\
\hline Truncus arteriosus Type 1 & $\begin{array}{l}\text { RVOTR with conduit, VSD } \\
\text { repair }\end{array}$ & Biological valved conduit & PC \\
\hline $\begin{array}{l}\text { C-TGA, VSD, PS, } \\
\text { dextrocardia }\end{array}$ & $\begin{array}{l}\text { RVOTR with conduit, VSD } \\
\text { repair }\end{array}$ & Biological valved conduit & PC \\
\hline CAVSD, L-AVVR, R-AVVR & No & & R-AWV \\
\hline Chronic kidney failure & No & Dialysis catheter & TV \\
\hline Premature-NICU hosp & No & Central catheter & RA fungus ball \\
\hline Chronic malnutrition & No & Central catheter & IVC-RA fungus ball \\
\hline $\mathrm{ARF}, \mathrm{AR}, \mathrm{MR}$ & No & & $\mathrm{AV}$ \\
\hline$A R F, M R, A R$ & MVR & Prosthetic MV & $\mathrm{LA}$ \\
\hline ARF, AR & AVR & Prosthetic AV & Prosthetic AV \\
\hline
\end{tabular}

$A B V=$ aortic balloon valvuloplasty; $A P V=a b s e n t$ pulmonary valve; $A R=$ aortic regurgitation; $A R F=$ acute rheumatic fever; $A S=$ aortic stenosis; $\mathrm{ASD}=$ atrial septal defect; $\mathrm{ASO}=$ arterial switch operation; $\mathrm{AV}=$ =aortic valve; $\mathrm{AVR}=$ aortic valve replacement; $\mathrm{BAV}=$ bicuspid aortic valve; $\mathrm{BCA}=$ balloon coarctation angioplasty; $\mathrm{BT}=$ Blalock-Taussig; $\mathrm{C}-\mathrm{TGA}=$ corrected transposition of the great arteries; $\mathrm{CAVSD}=$ complete atrioventricular septal defect; $C O A=$ coarctation of the aorta; $D O R V=$ double outlet right ventricle; $D S M=$ discrete subaortic membrane; IVC=inferior vena cava; L-AVVR=left atrioventricular valve regurgitation; $L A=l$ eft atrium; $L V O T=l$ eft ventricle outflow tract; $\mathrm{MR}=$ mitral regurgitation; $\mathrm{MV}=$ mitral valve; $\mathrm{MVR}=$ mitral valve replacement; $\mathrm{NICU}=$ neonatal intensive care unit; $\mathrm{PA}=$ pulmonary atresia; PAVSD=partial atrioventricular septal defect; PC=pulmonary conduit; PS=pulmonary stenosis; PTFE=polytetrafluoroethylene; $\mathrm{PV}=$ pulmonary valve; $\mathrm{R}-\mathrm{AVV}=$ right atrioventricular valve; $\mathrm{R}-\mathrm{AVVR}=$ right atrioventricular valve regurgitation; $\mathrm{RA}=$ right atrium; RVOTR=right ventricular outflow tract reconstruction; TGA=transposition of the great arteries; TOF=tetralogy of Fallot; TV=tricuspid

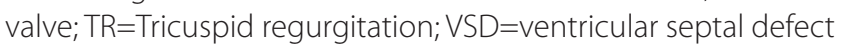

insufficiency associated with RHD, one underwent mitral valve replacement due to severe mitral valve insufficiency associated with RHD, and one underwent aortic valve replacement after balloon valvuloplasty due to bicuspid aortic valve disease and aortic valve stenosis. The time between prosthetic valve replacement and IE in these patients was three months, two years, and eight years, respectively. One patient developed complete atrioventricular block after surgery to repair tetralogy of Fallot and had a dual-chamber pacemaker.
Notably, $25.5 \%$ of the patients had a history of infection in the month before IE. Of these, three patients had pneumonia, two had acute gastroenteritis, one had open wound infection, and six had untreated dental caries. Furthermore, 59.6\% of the patients had undergone open heart surgery for CHD or acquired heart disease and $6.4 \%$ received a therapeutic intervention before the IE episodes. In our study, $10 \%$ of the IE episodes developed in the initial six months after cardiac surgery. The mean time between previous surgery and/or therapeutic intervention and IE attack 
was 4.5 \pm 3.7 years (minimum: 3.6 months; maximum: 13 years). Moreover, $34 \%$ of the patients had no history of interventional cardiac procedures or cardiac surgery before IE.

IE episodes were community-acquired in 44 patients (93.6\%), and IE was associated with intracardiac foreign bodies in five patients. Three patients had hospital-acquired IE. Two of the latter patients were followed up after central catheterization with broad-spectrum antibiotic therapy in the intensive care unit, but echocardiographic examination (performed because of reproduction of Candida albicans in repeated blood cultures) revealed a fungus ball.

Fourteen IE episodes occurred in patients with a biological valved conduit in the pulmonary position. All were bovine jugular vein conduits (ContegraTM Pulmonary Valved Conduit, Medtronic, Minneapolis, United States of America). None of the patients had received a homograft in the pulmonary position.

In $55.3 \%$ of the patients, diagnosis could be performed in the initial 10 days after the onset of symptoms. The mean time from the onset of the first symptom to diagnosis was 10.9 days (range: 4-32 days). An increase in the incidence of IE has been observed after 2010, with 31 patients (66\%) being diagnosed between 2011 and 2017.

\section{Clinical Finding}

The most common symptoms and signs detected in the patients were fever $\left(\geq 38{ }^{\circ} \mathrm{C}\right)(89.3 \%)$, leukocytosis (80.8\%), splenomegaly (70.2\%), new heart murmur or changing of preexisting murmur (68\%), fatigue (61.7\%), and anorexia (55.3\%). The mean erythrocyte sedimentation rate was $45.6 \mathrm{~mm} / \mathrm{h}$ (range: $8-86 \mathrm{~mm} / \mathrm{h}$ ), and the mean CRP was $74.6 \mathrm{mg} / \mathrm{dl}$ (range: 10-130 mg/dl) (Table 2). Congestive heart failure was noted in $14.9 \%$ of the patients at the time of diagnosis. Accompanying immunological and vascular phenomena included septic pulmonary embolism in $14.9 \%$ of the IE episodes, rheumatoid factor positivity in $12.7 \%$, pulmonary embolism in 10.6\%, Janeway lesions in $10.6 \%$, splinter hemorrhages in $8.5 \%$, and major arterial embolism in $8.5 \%$.

\section{Echocardiography}

Vegetation was observed via TTE in 40 patients (85.1\%) with IE episodes (Figure 1) and via TEE in five of seven without vegetation observed on TTE. These seven patients showed growth of the causative microorganism in their blood cultures. Two patients who did not show vegetation on TTE and TEE were treated as patients with IE because they showed microorganism growth in repeated blood cultures and IE diagnosis was supported based on meeting the minor criteria. In IE, vegetation was observed in the right heart structures in $62.2 \%$ of the patients, in the left heart structures in $31.1 \%$, and in structures of both sides in $4.4 \%$ (Table 3).

\section{Causative Microorganisms}

In $68.1 \%$ of the IE episodes (32 patients), growth of the causative microorganism in blood culture was observed. Streptococcus viridans (19.1\%), Staphylococcus aureus (14.8\%), and coagulase-negative Staphylococci (CoNS) (10.6\%) were the most commonly isolated agents (Table 4). Central catheterization was associated with IE in one of five patients with coagulase-negative staphylococcal endocarditis. In 31.9\% of the IE episodes, no microorganism growth in blood culture was observed. Microorganisms from the Haemophilus species, Aggregatibacter species, Cardiobacterium hominis, Eikenella corrodens, and Kingella species (HACEK) group were detected in two patients. Eikenella corrodens reproduction was detected in one patient and Cardiobacterium hominis reproduction in the other. C. albicans-induced fungus balls were detected in two patients who were followed up after central catheterization with broad-spectrum antibiotic therapy. Furthermore, $60 \%$ of patients with culture-negative IE received antibiotic treatment before the blood culture test.

\section{Prognosis}

In two patients, IE recurred within a six-month interval. Of these, one patient underwent arterial switch operation following the diagnosis of transposition of the great arteries (TGA), VSD, and atrial septal defect (ASD). In blood cultures, CoNS and

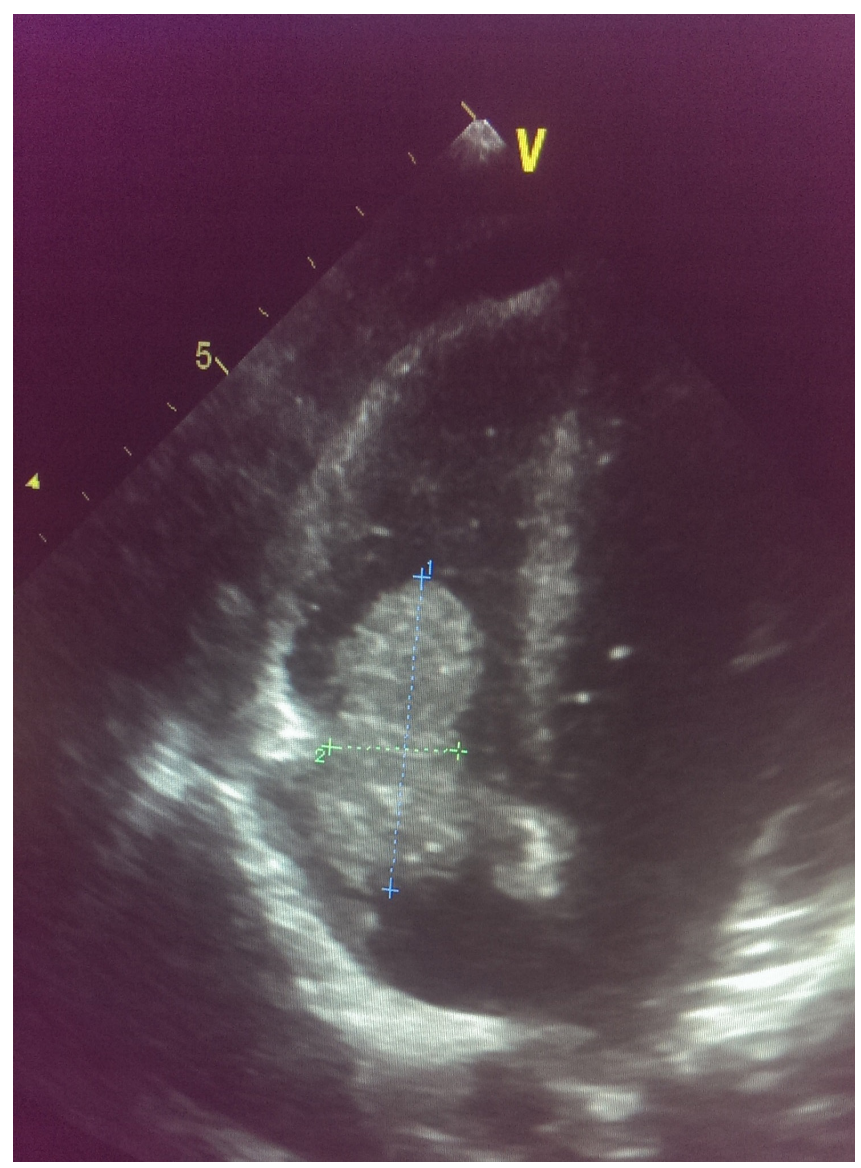

Fig. $\mathbf{1}$ - In a patient with a permanent dialysis catheter, vegetation is observed on the tricuspid valve. 
Table 2. Clinical and laboratory features of patients with infective endocarditis episode.

\begin{tabular}{|c|c|c|}
\hline Endocarditis episode $(n=47)$ & Mean (min-max) & n (\%) \\
\hline Female/male & & $11 / 34$ \\
\hline Age of patients (years) & 7.6 years ( 72 days -16 years) & \\
\hline Fever $\left(\geq 38^{\circ} \mathrm{C}\right)$ & & $42(89.3)$ \\
\hline Splenomegaly & & $33(70.2)$ \\
\hline New murmur/change of murmur & & $32(68)$ \\
\hline Body weight loss in patients & & $18(38.2)$ \\
\hline Hepatomegaly & & $16(34)$ \\
\hline Hematuria & & $10(21.2)$ \\
\hline Arthritis/arthralgia & & $4(8.5)$ \\
\hline Leukocytosis & & $38(80.8)$ \\
\hline Erythrocyte sedimentation velocity (mm/h) & $45.6(8-86)$ & \\
\hline C-reactive protein (mg/dl) & $74.6(10-130)$ & \\
\hline Anemia & According to age & $18(38.3)$ \\
\hline Tachycardia & According to age & $22(46.8)$ \\
\hline Cough & & $20(42.5)$ \\
\hline Debility & & $29(61.7)$ \\
\hline Myalgia & & $10(21.3)$ \\
\hline Abdominal pain & & $3(6.4)$ \\
\hline Anorexia & & $26(55.3)$ \\
\hline Dyspnea & & $14(29.8)$ \\
\hline Chest pain & & $8(17)$ \\
\hline Rheumatoid factor positivity & & $6(12.7)$ \\
\hline Janeway lesion & & $5(10.6)$ \\
\hline Glomerulonephritis & & $3(6.4)$ \\
\hline Osler nodule & & $2(4.2)$ \\
\hline Roth spot & & $3(6.4)$ \\
\hline Splinter hemorrhage & & $4(8.5)$ \\
\hline AST elevation & & $2(4.2)$ \\
\hline ALT elevation & & $5(10.6)$ \\
\hline Creatinine elevation & & $1(2.1)$ \\
\hline Headache & & $2(4.2)$ \\
\hline Vomiting & & $2(4.2)$ \\
\hline
\end{tabular}

ALT=alanine aminotransferase; AST=aspartate aminotransferase

Enterococcus faecalis growth was noted. One patient who had undergone total surgical correction using conduit had a double-outlet right ventricle, VSD, and pulmonary stenosis (PS). This patient underwent a second conduit replacement due to conduit vegetation. In blood cultures, CoNS and S. aureus growth was noted.

Congestive heart failure developed in one patient while receiving antibiotic treatment following the diagnosis of VSD and pneumonia. Echocardiographic examination of this patient revealed a $20-\times 25-\mathrm{mm}$ abscess between the right atrium and aorta. In blood culture, vancomycin-resistant S. aureus growth was noted. In this patient, while receiving antibiotic and anticongestive therapies, septic shock developed within a short period and the patient died despite all interventions. All patients were treated with antibiotic treatment. In addition to antibiotic treatment, 37 of the IE episodes (78.7\%) were treated with surgical 
intervention. The mean duration of preoperative antibiotic use was $8.5 \pm 2.2$ days (range: 5-12 days). Surgical indications were determined to be the removal of infected prosthetic material in 14 patients, intervention for CHD accompanying IE in 11, removal of large and mobile vegetation in seven, severe valve dysfunction in four, and removal of fungus ball in two.

Table 3. Vegetation location and frequency.

\begin{tabular}{l|c}
\hline Vegetation location & $\mathbf{n}(\%)$ \\
\hline Pulmonary valve & $16(30.7)$ \\
\hline Tricuspid valve & $10(19.2)$ \\
\hline Aortic valve & $10(19.2)$ \\
\hline Mitral valve & $5(9.6)$ \\
\hline Right ventricle & $3(5.7)$ \\
\hline Right atrium & $3(5.7)$ \\
\hline Left ventricle & $3(5.7)$ \\
\hline Left atrium & $1(1.9)$ \\
\hline Inferior vena cava & $1(1.9)$ \\
\hline Total & $52(100)$ \\
\hline
\end{tabular}

Note: Some patients had vegetation in multiple areas.
IE-related complications developed in $27.6 \%$ of the patients (Table 5). Left hemiparesis due to intracranial embolism developed in two patients and total occlusion in the right superior vena cava in one patient. The mean length of hospital

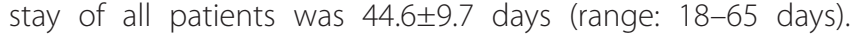
Additionally, $77.7 \%$ of the patients recovered without any sequelae with antibiotic and/or surgical treatment, but $14.8 \%$ of the IE episodes resulted in death. S. aureus reproduced in three of seven cases that resulted in death.

\section{DISCUSSION}

$\mathrm{IE}$ is more common in adults than in children. However, as a result of the increase in invasive surgery and medical interventions, particularly for cardiovascular diseases, the incidence of $\mathrm{IE}$ in children has started to increase ${ }^{[3]}$. Because of a decrease in the incidence of RHD-associated heart valve diseases in children in developed countries, IE usually develops secondary to $\mathrm{CHD}^{[3-5]}$. However, in these countries, while there has been a decrease in the number of patients with underlying RHD-associated heart valve disease, there has been a significant increase in the incidence of prosthetic valve endocarditis ${ }^{[6,7]}$. Reportedly, IE involvement in native pulmonary valve is very rare ${ }^{[8,9]}$. In our study, the underlying risk factor for IE was CHD in $85 \%$ of the IE episodes. RHD was a risk factor in a small proportion of our patients (6.4\%), possibly because our center is a reference center for CHD. In the literature, pediatric patients diagnosed with IE are accompanied by CHD with a range of $41.7 \%-81 \%[4,5,10-14]$.

Table 4. Microorganisms isolated in infective endocarditis episode.

\begin{tabular}{l|c|c}
\hline Microorganisms & Endocarditis episode (n) & Incidence (\%) \\
\hline Streptococcus viridans & 9 & 19.1 \\
\hline Staphylococcus aureus & 7 & 14.8 \\
\hline Methicillin-resistant & 4 & \\
\hline Methicillin-sensitive & 5 & 10.6 \\
\hline Coagulase-negative staphylococci & 3 & \\
\hline Methicillin-resistant & 2 & 2.1 \\
\hline Methicillin-sensitive & 1 & 2.1 \\
\hline Eikenella corrodens & 1 & 4.2 \\
\hline Cardiobacterium hominis & 2 & 4.2 \\
\hline Pseudomonas aeruginosa & 2 & 4.2 \\
\hline Candida albicans & 2 & 2.1 \\
\hline Enterococcus fecalis & 1 & 2.1 \\
\hline Brucella melitensis & 1 & 2.1 \\
\hline Escherichia coli & 1 & 31.9 \\
\hline Burkholderia cepacia & 15 & $\mathbf{1 0 0}$ \\
\hline Culture negative endocarditis & $\mathbf{4 7}$ & \\
\hline Total & & \\
\hline
\end{tabular}


In many studies, the risk of IE in CHDs was found to be higher in the left heart structures ${ }^{[15-17]}$. In contrast to findings reported in the literature, vegetation in IE was determined mostly in the right heart structures in most of our patients (62.2\%).

In epidemiological studies, the incidence of IE in the general population has been calculated to be 15-60/1,000,000 individuals per year in adults and 3.9-6.4/1.000.000 individuals-year in children ${ }^{[18,19]}$. While the incidence of IE is $11 / 10,000$ individualsyear in adults with CHD, this rate was reported to be three times lower $\left(4.1 / 10,000\right.$ individuals-year) in the pediatric group ${ }^{[15,17]}$. In a study by Rosenthal et al[.]3, the predisposing factor was identified as heart disease in $72 \%$ of patients with IE. In the literature, the incidence of IE in CHD has been reported to be 35\%-51\% in children with complex, cyanotic CHD ${ }^{[5,12,13]}$. In our study, the incidence of $\mathrm{CHD}$ was as high as $85 \%$ probably because children with $\mathrm{CHD}$ are monitored more intensively at our center.

Although a gradual improvement in surgical treatments for CHD has led to prolonged survival in these patients, it has also increased the risk of long-term complications such as IE. Rushani et al. ${ }^{[15]}$ reported that children with $\mathrm{CHD}$ aged $<3$ years had a relatively high risk of IE within six months after cardiac surgery, and this risk has increased by five times in these patients. Approximately $60 \%$ of our patients had a history of cardiac surgery before IE, with $10 \%$ of the IE episodes developed in the initial six months after cardiac surgery.

In recent years, with the improvements in surgical techniques, the survival rate in patients with CHD has increased. Increase in IE incidence has been observed with intracardiac prosthetic valve replacement, pacemaker implantation, and increased endovascular treatment ${ }^{[20,21]}$. The prosthetic material not only provides a surface that is susceptible to bacterial colonization but it is also often difficult to sterilize ${ }^{[15]}$. Complications such as abscess formation are considered to be more common in cases of prosthetic valve IE, but perivalvular abscess was not observed in the biological valved conduit or prosthetic valve cases in our study. In a study by Khoo et al. ${ }^{[14]}$ involving 138 IE cases, $19.6 \%$ of patients had previously undergone a heart valve replacement. In our study, biological valved conduit in right ventricularpulmonary artery (RV-PA) position in 14 patients, prosthetic aortic valve in two patients, and prosthetic mitral valve in one patient were important risk factors for IE.

In a study, Day et al. ${ }^{[1]]}$ reported that the incidence of IE showed a bimodal age distribution wherein it was most frequently observed in infants aged between 31 days and 11 months and in individuals aged 17-20 years. Gupta et al..[1] and Johnson et al. ${ }^{[4]}$ found that most patients diagnosed with IE were in the 6-18-year age group. Similarly, in our study, $68 \%$ of the patients were in the 6-18-year age group.

Although Beth Israel and other diagnostic criteria have been used for the diagnosis of IE in the past, the modified Duke criteria, which have higher sensitivity and specificity, are currently used in IE diagnosis ${ }^{[22,23]}$. Their use results in a higher definitive diagnosis rate (range: $70.8 \%-88 \%)^{[10,22-24]}$. On the other hand, in the presence of prosthetic valves or intracardiac devices, the sensitivity of the modified Duke criteria is low ${ }^{[25]}$. In our study, the number of patients with a definite diagnosis accounted for $72.3 \%$ of all patients.
Table 5. Complications in patients with infective endocarditis episode.

\begin{tabular}{l|c}
\hline Patients (n=13) & $\mathbf{n}(\mathbf{2 7 . 6 \% )}$ \\
\hline Heart failure & $7(14.9 \%)$ \\
\hline Septic pulmonary infarction & $7(14.9 \%)$ \\
\hline Pulmonary embolism & $5(10.6 \%)$ \\
\hline Pneumonia & $5(10.6 \%)$ \\
\hline Pleural effusion & $4(8.5 \%)$ \\
\hline Major arterial embolism & $4(8.5 \%)$ \\
\hline Intracranial embolism & $3(6.4 \%)$ \\
\hline Pericardial effusion & $3(6.4 \%)$ \\
\hline Left hemiparesis & $2(4.2 \%)$ \\
\hline Hemoptysis & $1(2.1 \%)$ \\
\hline Mycotic aneurysm & $1(2.1 \%)$ \\
\hline Convulsion & $1(2.1 \%)$ \\
\hline Paresthesia in the left leg & $1(2.1 \%)$ \\
\hline Altered mental status & $1(2.1 \%)$ \\
\hline SVC occlusion & $1(2.1 \%)$ \\
\hline Tricuspid valve injury & $1(2.1 \%)$ \\
\hline Note: Some patients have mulp & \\
\hline
\end{tabular}

Note: Some patients have multiple complications.

SVC=superior vena cava

The most common symptoms of IE are fever and weight loss ${ }^{[13]}$. In our study, fever was the most common symptom followed by weight loss. Because of the early admission of pediatric patients, conditions such as Osler's nodes and splinter hemorrhages are less common in children than in adults ${ }^{[13]}$. Similarly, the incidence of these conditions was low in our patients. In a study by Martin et al.. ${ }^{[13]}$, splenomegaly was detected in $7 \%$ of patients, whereas its rate was very high in our patients (68.9\%). In IE cases, vascular and immunological phenomena continue to be common $(10,26)$. Issa et al. ${ }^{[27]}$ reported that the time from the onset of symptoms to IE diagnosis was $49.6 \pm 64.5$ days (range: 1-731 days) and that $25 \%$ of cases were diagnosed within the initial 10 days after the onset of symptoms. In our study, $55.3 \%$ of the patients were diagnosed with the conditions 10 days after the onset of symptoms. The fact that vascular and immunological phenomena were lower than those reported in the literature may be due to the early diagnosis and early treatment of IE.

TTE and TEE are the most important methods of diagnosis, treatment, and follow-up of patients with $\mathrm{IE}^{[14,20,28,29]}$. In various studies, its sensitivity in IE diagnosis was found to be between $51 \%$ and $70 \%$, respectively ${ }^{[4,5,13,30,31]}$. Penk et al. ${ }^{[32]}$ reported that TTE had a sensitivity of $97 \%$ in pediatric patients with IE weighing $<60 \mathrm{~kg}$. Although the sensitivity of echocardiography has increased in IE diagnosis in recent years, echocardiography 
positivity has been found to be higher in patients with normal cardiac anatomy and lower in those with complex CHD. Further, it has been considered that high echocardiography positivity in patients with normal cardiac anatomy might be associated with the initial consideration of IE in their differential diagnosis ${ }^{[5,12,29]}$. TEE is reportedly not necessary for IE diagnosis in most of patients because TTE is sufficient for IE diagnosis in childhood ${ }^{[33]}$. In the presence of a prosthetic valve, if there are very small vegetations $(<2 \mathrm{~mm})$, no vegetation, or vegetation has been embolized, identification of vegetation can be extremely difficult even if TEE is used ${ }^{[34]}$. However, compared with TEE, multislice $\mathrm{CT}$ has been reported to provide good results in the evaluation of the perivalvular dimension of IE-related valve abnormalities, particularly abscess or pseudoaneurysms ${ }^{[35]}$. In our cases, typical vegetation was seen to a large extend with TTE (85\%). In a small number of cases wherein TTE could not determine typical vegetation, TEE was used successfully. When used together, the positivity rate of TTE/TEE was $95.7 \%$. Multislice CT was performed in two patients with a prosthetic valve to confirm the diagnosis.

Webb et al. ${ }^{[10]}$ reported that the left heart structures were involved in 53\% of the IE episodes, the right heart structures in 29\%, and both structures in 3.5\%. They reported that they could not determine the involved heart structures in 14\% of the IE episodes. Tseng et al. ${ }^{[36]}$ reported that the right heart structures were involved in $61.2 \%$ of IE episodes, left heart structures in $29.3 \%$, and both structures in 6.9\%. In our cases, vegetation was determined in all heart structures, although it was more common in the right heart structures (Table 2). In two patients, no vegetation was identified on TTE/TEE.

In IE episodes in childhood, the most common causative agent is S. viridians, followed by S. aureus and Enterococcus spp. $[3-6,11,13,21,24,32,37]$. While the risk of IE caused by $S$. aureus-caused bacteremia was found to be low in previous studies, S. aureus has started to be seen more frequently in community- and hospitalacquired IE in the past two decades ${ }^{[3,10,38-40]}$. In our study, the most common microorganisms were S. viridans, S. aureus, and CoNS (Table 3). E. faecalis-induced IE has been reported at a ratio of $2 \%-6 \%$ in other studies ${ }^{[3-5,13]}$ and $4.2 \%$ in our study. Brucella melitensis, a gram-negative coccobacillus, was isolated in one patient. Brucellosis (zoonosis transmitted from sheep and goats) is rarely (0.5\%) a cause of IE in children ${ }^{[41]}$.

In the HACEK group of microorganisms, which are slowgrowing gram-negative bacteria, the most common cause of endocarditis is $H$. parainfluenza $e^{[42]}$. Endocarditis caused by $E$. corrodens, which frequently colonizes the oropharynx, has been reported in only two (3\%) of $76 \mathrm{IE}$ episodes by Martin et al. ${ }^{[13]}$ to date. In our study, E. corrodens was isolated in one IE episode (2.1\%). In the literature, apart from these, no case of IE in children caused by E. corrodens has been reported. In a study in Spain, the HACEK group of microorganisms was found to be responsible for only $1.3 \%$ of 1209 IE cases in adults, but E. corrodens was not isolated from any patient in that study ${ }^{[43]}$.

Burkholderia cepacia, which causes infections in patients with cystic fibrosis and granulomatous disease, is a rare cause of IE. In our study, B. cepacia was detected as a causative agent in one patient. In this patient, modified Blalock-Taussig shunt was performed at the age of three months following the diagnosis of
TGA, VSD, ASD, and PS. Native pulmonary valve IE was observed three months after cardiac surgery, and B. cepacia growth was observed in blood cultures. After two-week antibiotic treatment, the vegetations on the pulmonary valve were cleared, RV-PA connection was achieved with conduit insertion, and the Rastelli procedure was performed. To date, B. cepacia has been reported as an IE agent only in one newborn ${ }^{[44]}$.

IE-related mortality in the pediatric group is between $4 \%$ and $24 \%^{[3-5,11-14,21]}$. The main factors affecting the prognosis in IE are the presence and severity of complications, characteristics of the causative microorganism, and echocardiographic findings. High risks of morbidity and mortality have been reported in patients with congestive heart failure, perianal complications, or $S$. aureus-caused endocarditis ${ }^{[6,10,21]}$. In these patients, the need for surgical treatment in the active stage of the disease is high ${ }^{[6,10,45]}$. The most significant risk factors for mortality in patients with no previous heart disease are the neonatal period and S. aureuscaused endocarditis, which depend more on frequent cardiac complications in these patients ${ }^{[5,12,13]}$. In our study, no specific distribution in terms of CHD in patients with mortality was observed.

The mortality rate in Candida-caused IE has been reported to be approximately $90 \%{ }^{[28]}$. In our study, excision of a fungus ball was surgically performed with antifungal treatment in two patients with Candida IE, following which full recovery was achieved.

The most common complications in our patients were congestive heart failure, septic pulmonary embolism, pulmonary embolism, and major arterial embolism. Congestive heart failure and embolic phenomena were the most significant factors to have an impact on mortality and morbidity in our patients. In addition, the characteristics of causative microorganisms were associated with poor results. S. aureus reproduction was found to be associated with a high rate of mortality in our study. Rapid identification of patients at high risk of death may provide an opportunity to improve the prognosis of IE.

\section{Limitations}

A retrospective study is a significant disadvantage in the collection and evaluation of data.

\section{CONCLUSION}

$\mathrm{CHD}$ is an increasingly significant riskfactor for IE. The presence of a biological valved conduit and unoperated large VSD were two important risk factors for IE in our patients. Furthermore, we observed high mortality rate associated with S. aureus infection. Even if echocardiographic examination findings are normal in patients with CHD on follow-up, particularly in those with fever of unknown cause, who have undergone surgery and have been implanted with prosthetic devices, examination and treatment should be performed in favor of IE.

\section{No financial support.}

No conflict of interest. 


\section{Authors' roles \& responsibilities}

KY Substantial contributions to the conception or design of the work; or the acquisition, analysis, or interpretation of data for the work; drafting the work or revising it critically for important intellectual content; agreement to be accountable for all aspects of the work in ensuring that questions related to the accuracy or integrity of any part of the work are appropriately investigated and resolved; final approval of the version to be published

ZE

Substantial contributions to the conception or design of the work; or the acquisition, analysis, or interpretation of data for the work; drafting the work or revising it critically for important intellectual content; agreement to be accountable for all aspects of the work in ensuring that questions related to the accuracy or integrity of any part of the work are appropriately investigated and resolved; final approval of the version to be published

NKT Substantial contributions to the conception or design of the work; or the acquisition, analysis, or interpretation of data for the work; drafting the work or revising it critically for important intellectual content; agreement to be accountable for all aspects of the work in ensuring that questions related to the accuracy or integrity of any part of the work are appropriately investigated and resolved; final approval of the version to be published

BV Drafting the work or revising it critically for important intellectual content; agreement to be accountable for all aspects of the work in ensuring that questions related to the accuracy or integrity of any part of the work are appropriately investigated and resolved; final approval of the version to be published

MO Drafting the work or revising it critically for important intellectual content; agreement to be accountable for all aspects of the work in ensuring that questions related to the accuracy or integrity of any part of the work are appropriately investigated and resolved; final approval of the version to be published

\section{REFERENCES}

1. Gupta S, Sakhuja A, McGrath E, Asmar B. Trends, microbiology, and outcomes of infective endocarditis in children during 2000-2010 in the United States. Congenit Heart Dis. 2017;12(2):196-201. doi:10.1111/ chd. 12425

2. Li JS, Sexton DJ, Mick N, Nettles R, FowlerVG Jr, Ryan T, et al. Proposed modifications to the Duke criteria for the diagnosis of infective endocarditis. Clin Infect Dis. 2000;30(4):633-8. doi:10.1086/313753.

3. Rosenthal LB, Feja KN, Levasseur SM, Alba LR, Gersony W, Saiman L. The changing epidemiology of pediatric endocarditis at a children's hospital over seven decades. Pediatr Cardiol. 2010;31(6):813-20. doi:10.1007/ s00246-010-9709-6.

4. Johnson JA, Boyce TG, Cetta F, Steckelberg JM, Johnson JN. Infective endocarditis in the pediatric patient: a 60-year single-institution review. Mayo Clin Proc. 2012;87(7):629-35. doi:10.1016/j.mayocp.2012.02.023.

5. Coward K, Tucker N, Darville T. Infective endocarditis in Arkansan children from 1990 through 2002. Pediatr Infect Dis J. 2003;22(12):1048-52. doi:10.1097/01.inf.0000101186.88472.b5.
6. Ware AL, Tani LY, Weng HY, Wilkes J, Menon SC. Resource utilization and outcomes of infective endocarditis in children. J Pediatr. 2014;165(4):80712.e1. doi:10.1016/j.jpeds.2014.06.026.

7. Tleyjeh IM, Abdel-Latif A, Rahbi H, Scott CG, Bailey KR, Steckelberg $J M$, et al. A systematic review of population-based studies of infective endocarditis. Chest. 2007;132(3):1025-35. doi:10.1378/chest.06-2048.

8. Liekiene D, Bezuska L, Semeniene P, Cypiene R, Lebetkevicius V, Tarutis $V$, et al. Surgical treatment of infective endocarditis in pulmonary position-15 years single centre experience. Medicina (Kaunas). 2019;55(9):608. doi:10.3390/medicina55090608.

9. Deng H, Ma Y, Zhai H, Miao Q. Surgical valve repair of isolated pulmonary valve endocarditis. Interact Cardiovasc Thorac Surg. 2013;16(3):384-6. doi:10.1093/icvts/ivs509.

10. Webb R, Voss L, Roberts S, Hornung T, Rumball E, Lennon D. Infective endocarditis in New Zealand children 1994-2012. Pediatr Infect Dis J. 2014;33(5):437-42. doi:10.1097/INF.0000000000000133.

11. Day MD, Gauvreau K, Shulman S, Newburger JW. Characteristics of children hospitalized with infective endocarditis. Circulation. 2009;119(6):865-70. Erratum in: Circulation. 2010;122(21):e560. doi:10.1161/CIRCULATIONAHA.108.798751.

12. Saiman L, Prince A, Gersony WM. Pediatric infective endocarditis in the modern era. J Pediatr. 1993;122(6):847-53. doi:10.1016/s00223476(09)90006-3.

13. Martin JM, Neches WH, Wald ER. Infective endocarditis: 35 years of experience at a children's hospital. Clin Infect Dis. 1997;24(4):669-75. doi:10.1093/clind/24.4.669.

14. Khoo B, Buratto E, FrickeTA, Gelbart B, Brizard CP, Brink J, et al. Outcomes of surgery for infective endocarditis in children: a 30-year experience. J Thorac Cardiovasc Surg. 2019;158(5):1399-409. doi:10.1016/j. jtcvs.2019.06.024.

15. Rushani D, Kaufman JS, Ionescu-Ittu R, Mackie AS, Pilote L, Therrien J, et al. Infective endocarditis in children with congenital heart disease: cumulative incidence and predictors. Circulation. 2013;128(13):1412-9. doi:10.1161/CIRCULATIONAHA.113.001827.

16. Wilson W, Taubert KA, Gewitz M, Lockhart PB, Baddour LM, Levison M, et al. Prevention of infective endocarditis: guidelines from the American heart association: a guideline from the American heart association rheumatic fever, endocarditis, and Kawasaki disease committee, council on cardiovascular disease in the young, and the council on clinical cardiology, council on cardiovascular surgery and anesthesia, and the quality of care and outcomes research interdisciplinary working group. Circulation. 2007;116(15):1736-54. Erratum in: Circulation. 2007;116(15):e376-7. doi:10.1161/CIRCULATIONAHA.106.183095.

17. Verheugt CL, Uiterwaal CS, van der Velde ET, Meijboom FJ, Pieper PG, Veen $\mathrm{G}$, et al. Turning 18 with congenital heart disease: prediction of infective endocarditis based on a large population. Eur Heart J. 2011;32(15):1926-34. doi:10.1093/eurheartj/ehq485.

18. lung B, Vahanian A. Epidemiology of valvular heart disease in the adult. Nat Rev Cardiol. 2011;8(3):162-72. doi:10.1038/nrcardio.2010.202.

19. Schollin J, Bjarke B, Wesström G. Infective endocarditis in Swedish children. II. Location, major complications, laboratory findings, delay of treatment, treatment and outcome. Acta Paediatr Scand. 1986;75(6):9991004. doi:10.1111/j.1651-2227.1986.tb10330.x.

20. Yuan XC, Liu M, Hu J, Zeng X, Zhou AY, Chen L. Diagnosis of infective endocarditis using echocardiography. Medicine (Baltimore). 2019;98(38):e17141. doi:10.1097/MD.0000000000017141.

21. Cahill TJ, Jewell PD, Denne L, Franklin RC, Frigiola A, Orchard E, et al. Contemporary epidemiology of infective endocarditis in patients with congenital heart disease: a UK prospective study. Am Heart J. 2019;215:70-7. doi:10.1016/j.ahj.2019.05.014.

22. Stockheim JA, Chadwick EG, Kessler S, Amer M, Abdel-Haq N, Dajani $\mathrm{AS}$, et al. Are the Duke criteria superior to the Beth Israel criteria for 
the diagnosis of infective endocarditis in children? Clin Infect Dis. 1998;27(6):1451-6. doi:10.1086/515021.

23. Tissières $P$, Gervaix A, Beghetti M, Jaeggi ET. Value and limitations of the von Reyn, Duke, and modified Duke criteria for the diagnosis of infective endocarditis in children. Pediatrics. 2003;112(6 Pt 1):e467. doi:10.1542/peds.112.6.e467.

24. Lin YT, Hsieh KS, Chen YS, Huang IF, Cheng MF. Infective endocarditis in children without underlying heart disease. J Microbiol Immunol Infect. 2013;46(2):121-8. doi:10.1016/j.jmii.2012.05.001.

25. Habib G, Lancellotti P, Antunes MJ, Bongiorni MG, Casalta JP, Del Zotti F, et al. 2015 ESC guidelines for the management of infective endocarditis: the task force for the management of infective endocarditis of the European society of cardiology (ESC). Endorsed by: European association for cardio-thoracic surgery (EACTS), the European association of nuclear medicine (EANM). Eur Heart J. 2015;36(44):3075-128. doi:10.1093/ eurheartj/ehv319.

26. Thuny F, Di Salvo G, Belliard O, Avierinos JF, Pergola V, Rosenberg V, et al. Risk of embolism and death in infective endocarditis: prognostic value of echocardiography: a prospective multicenter study. Circulation. 2005;112(1):69-75. Erratum in: Circulation. 2005;112(9):e125. Disalvo, Giovanni [corrected to Di Salvo, Giovanni]; Calabro, Raffaello [corrected to Calabró, Raffaele]. doi:10.1161/CIRCULATIONAHA.104.493155.

27. Issa VS, Fabri J Jr, Pomerantzeff PM, Grinberg M, Pereira-Barreto AC, Mansur AJ. Duration of symptoms in patients with infective endocarditis. Int J Cardiol. 2003;89(1):63-70. doi:10.1016/s0167-5273(02)00424-2.

28. Habib G, Hoen B, Tornos P, Thuny F, Prendergast B, Vilacosta I, et al. Guidelines on the prevention, diagnosis, and treatment of infective endocarditis (new version 2009): the task force on the prevention, diagnosis, and treatment of infective endocarditis of the European society of cardiology (ESC). Endorsed by the European society of clinical microbiology and infectious diseases (ESCMID) and the International society of chemotherapy (ISC) for infection and cancer. Eur Heart J. 2009;30(19):2369-413. doi:10.1093/eurheartj/ehp285.

29. Kelly P, Hua N, Madriago EJ, Holmes KW, Shaughnessy R, Ronai C. The utility of echocardiography in pediatric patients with structurally normal hearts and suspected endocarditis. Pediatr Cardiol. 2020;41(1):62-8. doi:10.1007/s00246-019-02222-z.

30. Awadallah SM, Kavey RE, Byrum CJ, Smith FC, Kveselis DA, Blackman MS. The changing pattern of infective endocarditis in childhood. Am J Cardiol. 1991;68(1):90-4. doi:10.1016/0002-9149(91)90717-y.

31. Fukushige J, Igarashi $H$, Ueda K. Spectrum of infective endocarditis during infancy and childhood: 20-year review. Pediatr Cardiol. 1994;15(3):12731. doi:10.1007/BF00796324.

32. Penk JS, Webb CL, Shulman ST, Anderson EJ. Echocardiography in pediatric infective endocarditis. Pediatr Infect Dis J. 2011;30(12):110911. doi:10.1097/INF.0b013e31822d320b.

33. Humpl T, McCrindle BW, Smallhorn JF. The relative roles of transthoracic compared with transesophageal echocardiography in children with suspected infective endocarditis. J Am Coll Cardiol. 2003;41(11):206871. doi:10.1016/s0735-1097(03)00419-4.

34. Hill EE, Herijgers P, Claus P, Vanderschueren S, Peetermans WE, Herregods MC. Abscess in infective endocarditis: the value of transesophageal echocardiography and outcome: a 5-year study. Am Heart J. 2007;154(5):923-8. doi:10.1016/j.ahj.2007.06.028.

35. Feuchtner GM, Stolzmann P, DichtlW, SchertlerT, Bonatti J, Scheffel $H$, et al. Multislice computed tomography in infective endocarditis: comparison with transesophageal echocardiography and intraoperative findings. J Am Coll Cardiol. 2009;53(5):436-44. doi:10.1016/j.jacc.2008.01.077.

36. Tseng WC, Chiu SN, Shao PL, Wang JK, Chen CA, Lin MT, et al. Changing spectrum of infective endocarditis in children: a 30 years experiences from a tertiary care center in Taiwan. Pediatr Infect Dis J. 2014;33(5):46771. doi:10.1097/INF.0000000000000145.

37. Murdoch DR, Corey GR, Hoen B, Miró JM, Fowler VG Jr, Bayer AS, et al. Clinical presentation, etiology, and outcome of infective endocarditis in the 21st century: the international collaboration on endocarditisprospective cohort study. Arch Intern Med. 2009;169(5):463-73. doi:10.1001/archinternmed.2008.603.

38. Pasquali SK, He X, Mohamad Z, McCrindle BW, Newburger JW, Li JS, et al. Trends in endocarditis hospitalizations at US children's hospitals: impact of the 2007 American heart association antibiotic prophylaxis guidelines. Am Heart J. 2012;163(5):894-9. doi:10.1016/j.ahj.2012.03.002.

39. Mylotte JM, McDermott C, Spooner JA. Prospective study of 114 consecutive episodes of Staphylococcus aureus bacteremia. Rev Infect Dis. 1987;9(5):891-907. doi:10.1093/clinids/9.5.891.

40. Millar BC, Prendergast BD, Moore JE. Community-associated MRSA (CAMRSA): an emerging pathogen in infective endocarditis. J Antimicrob Chemother. 2008;61(1):1-7. doi:10.1093/jac/dkm410.

41. Kazaz H, Celkan MA, Ustunsoy H, Baspinar O. Mitral annuloplasty with biodegradable ring for infective endocarditis: a new tool for the surgeon for valve repair in childhood. Interact Cardiovasc Thorac Surg. 2005;4(4):378-80. doi:10.1510/icvts.2005.105833.

42. Feder HM Jr, Roberts JC, Salazar J, Leopold HB, Toro-Salazar O. HACEK endocarditis in infants and children: two cases and a literature review. Pediatr Infect Dis J. 2003;22(6):557-62. doi:10.1097/01. inf.0000069795.12338.cf.

43. Ambrosioni J, Martinez-Garcia C, Llopis J, Garcia-de-la-Maria C, Hernández-Meneses M, Tellez A, et al. HACEK infective endocarditis: epidemiology, clinical features, and outcome: a case-control study. Int J Infect Dis. 2018;76:120-5. doi:10.1016/j.ijid.2018.08.013.

44. Yonas E, Damay V, Pranata R, Nusarintowati N. Infective endocarditis due to Burkholderia cepacia in a neonate: a case report. J Med Case Rep. 2018;12(1):120. doi:10.1186/s13256-018-1633-z.

45. Rovery C, Greub G, Lepidi H, Casalta JP, Habib G, Collart F, et al. PCR detection of bacteria on cardiac valves of patients with treated bacterial endocarditis. J Clin Microbiol. 2005;43(1):163-7. doi:10.1128/ JCM.43.1.163-167.2005. 